\title{
๑๑®@ Suárez y la Filosofía Moderna
}

\author{
Giannina Burlando*
}

Resumen: Los intérpretes de hoy debaten sobre el estatuto y la asociación de Francisco Suárez con la Filosofía Moderna. Este estudio enfoca los principales aspectos de la filosofía especulativa y práctica del pensador jesuita, con el propósito de mostrar que, en las diversas disciplinas abordadas, Suárez ha tomado en cuenta genealógicamente, la formalización de las teorías precedentes: las ha re-formulado en términos metodológicos para progresar. A su preferencia parcial por pruebas a priori, agrega datos de experiencia con respecto a los postulados de la metafísica. Por otra parte, innova en la adopción del lenguaje médico imperante en materias de psicología moral y en la intrincación de las disciplinas teológicas y jurídica, en materias políticas. Con este proceder, que se distingue del estrictamente propedéutico para la investigación científica, alcanza una comprensión adecuada de los fenómenos y, a partir de sus replanteamientos establece el curso de figuras representativas del pensamiento moderno.

Palabras clave: Suárez; ontologia; epistemologia; psicología moral; filosofía política; filosofía moderna.

\section{Suárez and Modern Philosophy}

\begin{abstract}
Today's interpreters debate the status and association of Francisco Suárez with Modern Philosophy. This paper focuses on the main aspects of the speculative and practical philosophy of the Jesuit thinker, with the purpose of showing that, in the various disciplines approached, Suárez has taken into account genealogically the formalization of the preceding theories: he has reformulated them in methodological terms to progress. To his partial preference for a priori proofs, he adds data of experience regarding the postulates of metaphysics. On the other hand,
\end{abstract}

\footnotetext{
* Doutora em História da Filosofia pela Ohio State University. Professora na Pontificia Universidad Católica de Chile. E-mail: gburland@uc.cl. ORCID: https://orcid.org/0000-00026057-612X. Lattes: http://lattes.cnpq.br/0287393825859418.
} 
he innovates in the adoption of the prevailing medical language in matters of moral psychology and in the intricacy of theological and legal disciplines, in political matters. With this procedure, which differs from the strictly propaedeutic for scientific research, he reaches an adequate understanding of the phenomena and, from the rethinking of it, establishes the course of representative figures of modern thought.

Key-words: Suárez; ontology; epistemology; moral psicology; political philosophy; Modern philosophy.

\section{Suárez e a Filosofia Moderna}

Resumo: Os intérpretes de hoje debatem o estatuto e a associação de Francisco Suárez com a Filosofia Moderna. Este estudo enfoca os principais aspectos da filosofia especulativa e prática do pensador jesuíta, com o propósito de mostrar que, nas várias disciplinas abordadas, Suárez teve em conta genealogicamente a formalização das teorias precedentes: ele reformulou em termos metodológicos para o progresso. À sua preferência parcial por provas a priori, ele adiciona dados da experiência sobre os postulados da metafísica. Por outro lado, inova na adoção da linguagem médica predominante em questões de psicologia moral e na complexidade das disciplinas teológicas e jurídicas, em questões políticas. Com esse procedimento, que difere do estritamente propedêutico para a pesquisa científica, ele chega a uma compreensão adequada dos fenômenos e, a partir de seu repensar, estabelece o curso de figuras representativas do pensamento moderno.

Palavras-chave: Suárez; ontologia; epistemologia; psicologia moral; filosofia política; filosofia moderna.

"[...] pues toda virtud, salvo en la brevedad del reconocimiento, carece de resplandor y vive en una caverna oscura rodeada de otros habitantes, algunos muy peligrosos." (Roberto Bolaño, 2666, Barcelona: Alfaguara, 2016: 65) 


\section{Introducción $^{1}$}

El testimonio de las publicaciones recientes --tanto en obras colectivas como de autor- dedicadas a reinterpretar para el siglo XXI el pensamiento de Francisco Suárez, no sólo es señal de reconocimiento a la precedente negligencia que experimentó su legado y su significancia histórica, sino más bien destaca por subrayar que "el principal ímpetu para este renovado interés parece ser la manera en que el pensamiento de Suárez y su situación histórica, escapa a las categorizaciones convencionales del Renacimiento, Barroco, primera Modernidad y otras"2. La resistencia a tales cánones se explica en parte porque "en la época en la que Suárez muere, la filosofía estaba al borde de un proceso que nunca había experimentado antes en la historia: an intellectual movemenent originating among outsiders to the standard academic millieu would succeed in carrying through the ideas that the entire hitherto philosophical tradition has to be discarded and philosophy must make a fresh new start"3.

De manera que, dentro de tal radical giro programático, se juzga que "Without doubt Francisco Suárez was the main link between medieval and modern clasical philosophy" . De ahí que los interpretes expongan sobre

\footnotetext{
${ }^{1}$ Este artículo se deriva de mi participación en calidad de investigadora internacional del Proyecto I+D+i 2021-2024: "Ética y justicia cosmopolita en la Escuela Ibérica de la Paz y la Escolástica Iberoamericana: Aportaciones del pensamiento y tradición jesuita" (PEMOSJ2, ref. PID2020-112904RB-I00), cuyos investigadores principales son: J. A. Senent-De Frutos (IP1); E. Ibáñez Ruiz del Portal.

${ }^{2}$ Stephen Schloesser, "Book Reviews: Lukás Novák, ed. Suárez's Metaphysics in Its Historical and Systematic Context. Contemporary Scholasticism vol. 2. Berlin; Boston: De Gruyter, 2014. Victor M. Salas and Robert L. Fastiggi, eds. A Companion to Francisco Suárez. Brill's Companions to the Christian Tradition vol. 53. Leiden; Boston: Brill, 2015", Journal of Jesuit Studies, 3 (2016): 85. (hereafter, JJS).

3 Lukás Novák (ed.), Suárez's Metaphysics in Its Historical and Systematic Context, Contemporary Scholasticism, vol. 2 (Berlin, Boston: De Gruyter, 2014), 2. (hereafter, SMHC)

${ }^{4}$ John Doyle, Collected Studies of Francisco Suárez (Leuven: Leuven University Press, 2010), 3 .
} 
cómo el neo-escolasticismo de Suárez se traspasa a la filosofía moderna ${ }^{5}$; sobre cómo "la especificidad de su pensamiento reside en el hecho de que ilustra la transición de la filosofía medieval en la filosofía moderna" ${ }^{6}$; sobre cómo Suárez "es figura de central importancia en el desarrollo del escolasticismo moderno"7; sobre cómo se identifica un lugar "exquisitamente barroco" para Suárez en el cual la tradición se "vuelve" a la modernidad y, por consiguiente, forma con ella un nuevo "pliegue" 8 .

Así pues, a partir de diferentes descripciones y énfasis, se asocia a Suárez con la temprana modernidad, la modernidad clásica, o incluso la postmodernidad ${ }^{9}$. Sin embargo, resistiéndose a una sola clasificación, "Suárez provoca reconsideraciones sobre: ¿Qué hace moderna su modernidad?" 10 . La tendencia actual apunta a la modernidad ignaciana del pensador, quien se conformaría a las orientaciones normativas dinámicas de las rationes studiorum de la Compañía de Jesús (1586-1599) ${ }^{11}$. En línea con

${ }^{5}$ Leopoldo Prieto, “Ockham, Suárez y Descartes: transición de las noéticas tardomedievales a la filosofia moderna," Anales del Seminario de Historia de la Filosofía 33, no 1 (June 2016): $33-57$.

${ }^{6}$ Jean Paul Coujou, Le vocabulaire de Suárez (Paris: Ellipses, 2001), 3. (My transl.)

${ }^{7}$ Novák, $(S M H): 1$.

${ }^{8}$ Costantino Esposito (ed.) Jean- François Courtine Il sistema della metafísica. Tradizione aristotélica e svolta di Suárez (Milano: Vita e Pensiero, 1999), Cuoted by Schloesser, (SSJ): 90.

${ }^{9}$ Jean-Fraçois Courtine, Suárez et le sistème de la métaphysique (Paris: PUF, 1990) (Hereafter, SSM); Jean-Fraçois Courtine, "Suárez, Heidegger and Contemporary Metahphysics" in $A$ Companion to Francisco Suárez, eds. Victor Salas, Robert Fastiggi (Leiden, Boston: Brill, 2014) (Hereafter, ACTFS); José Pereira, "Original Features of Suárez's Thought" in (ACTFS), 312; Costantino Esposito, ““Al di sopra', 'atraverso', 'al di sopra'. Heidegger, Tomasso, Suárez nella historia della metafisica”, Giornale di metafísica 32 (2010): 553-586.

${ }^{10}$ Schloesser, (JJS): 85.

${ }^{11}$ Marco Forlivesi, "Francisco Suárez and the rationes studiorum of the Society of Jesus" in Francisco Suárez And His Legacy. The Impact Of Suarezian Metaphysics And Epistemology On Modern Philosophy, ed. Marco Sgarbi (Milano: Vita e pensiero, 2010); Victor Salas, Robert Fastiggi (ACTFS); Schloesser, (JJS); Exploring Jesuit Distinctiveness: Interdisciplinary Perspectives on Ways of Proceeding within the Society of Jesus, ed. Robert A. Maryks (Leiden: Brill, 2016); Juan Antonio Senent de Frutos, "Ignacian Modernity as another Kind of Modernity" in Reformation (en) und Moderne, eds. Hans Schelkshorn, Herman Westerink (Germany: Vienna University Press, 2017), 153-171; Senent, "Justicia y ecología como 
este marco discursivo, mi propósito es circunscribir aspectos de la modernidad filosófica de Suárez. No analizaré entonces las complejas categorías histórico-sociológicas de la denominada 'Cultura moderna', 'Sociedad moderna', 'Mundo moderno', 'Método y Revolución científica moderna'; sino que resumiré, en primer lugar, las principales doctrinas que Suárez, en tanto autor, re-formalizo y trasladó (translator) a los filósofos modernos, y en segundo lugar, haré alusión a lo que Gonçalo Pistacchini Moita en su libro, A Modernidade Filosófica de Francisco Suárez (2014) ${ }^{12}$, ha destacado fundamentalmente como: modernidad filosófica de Suárez, de lo cual se derivan algunas ventajas originales y la influencia del espíritu jesuita distintivo del pensador.

La modernidad en perspectiva y las doctrinas modernas de Suárez. Para varios intérpretes, Heidegger es quien principalmente puso a Suárez en el centro de la discusión filosófica de fines del siglo XX y, por tanto, quien impulsó los estudios que reconocen la influencia del padre jesuita en la modernidad y posmodernidad. Se han destacado pasajes en Sein und Zeit donde Heidegger, efectivamente, con respecto a la metafísica, juzgó que: "En la acuñación escolástica la ontología griega pasa, en lo esencial, por el camino de las Disputaciones metaphysicae de Suárez, a la metafísica y la filosofía trascendental de la Edad Moderna, y determina aún los fundamentos y las metas de la lógica de Hegel” (Sein und Zeit, 1927, §6) ${ }^{13}$. $\mathrm{O}$ se hace referencia a los parágrafos en Die Grundprobleme der

frontera para las universidades jesuitas." Arbor, Ciencia, Pensamiento y Cultura, 192-782 (Noviembre Diciembre 2016): 1-14.

12 Gonçalo Pistacchini Moita, A Modernidade Filosófica de Francisco Suárez (Lisboa: Imprensa Nacional, Casa da Moeda, 2014), (hereafter, $A M F S$ ).

${ }_{13}$ Martín Heidegger, El Ser y el Tiempo, trad. de José Gaos (México: Fondo de Cultura Económica, 1951), §6. 
Phänomenologie ${ }^{14}$, donde Heidegger vuelve a llamar la atención sobre la fuerte influencia, la sistematización, que imprime el modo científico suareciano, pero sobre todo, destacando su carácter de primer líder en ontología, cuando afirma que: "Suárez fue el pensador que más poderosamente influyó en la filosofía moderna [...] Fue Suárez quien sistematizó por primera vez la filosofía medieval, sobre todo la ontología [...], pues Suárez trató de suplir esta carencia [la incoherencia de la Metafísica de Aristóteles] disponiendo, por vez primera, los problemas ontológicos en una forma sistemática, que determinó una división de la metafísica que perduró durante los siglos siguientes hasta Hegel" ${ }^{15}$. Además, Heidegger considera que la disposición de las disciplinas filosóficas centrales diseñada por Suárez, se asimila en la Crítica de la razón pura de Kant ${ }^{16}$.

Otros dictámenes de Heidegger -en los Grundbegriffe der Metaphysik: Welt-Endlichkeit-Einsamkeit ${ }^{17}$ - sin lugar a dudas definieron el estado hermenéutico actual de la investigación, pues notó allí que: "La importancia de Suárez como teólogo y filósofo está lejos de ser reconocida al punto que merece este pensador, quien debe ser ubicado incluso por sobre Tomás de Aquino, en términos de su ingenio e independencia de cuestionamientos. Su importancia para el desarrollo y la conformación de la

\footnotetext{
${ }^{14}$ Martin Heidegger, Die Gundprobleme der Phänomenologie, Gesamtausgabe, vol. 24, ed. F. W. von Hermann (Frankfurt, 1975); [Traducción castellana Los Problemas Fundamentales de la Fenomenología, Madrid: Trotta, 2000] (Hereafter, PFF).

${ }^{15}$ Heidegger, $(P F F), 112$.

${ }^{16}$ En la disposición que hace Suárez de las disciplinas filosóficas centrales se distingue, según la descripción de Heidegger: una metaphyca generalis, una ontología general, y una metaphysica specialis, cosmologia rationalis, ontología de la naturaleza, psychologia rationalis, ontología del espíritu, y una theologia rationalis, ontología de Dios (Heidegger, $(P F F), 112)$.

17 Martin Heidegger, Grundbegriffe der Metaphysik: Welt-Endlichkeit-Einsamkeit, Gesamtausgabe, II. (Abteilung: Vorlesungen 1923-1944, Band 29/30. Frankfurt am Main: Vittorio Klostermann, 1976). [English transl. The Fundamental Concepts of Metaphysics: World, Finitude, Solitude, (Blommington and Indianapolis: Indiana University Press, 1995) (Hereafter, FCM).
} 
metafísica moderna no es meramente formal, en el sentido que bajo su influencia la disciplina metafísica se configura de una forma específica. Igualmente es tan importante su modulación de los problemas concernientes a contenidos que renacen en la filosofía moderna"18. Finalmente, otra premisa de Heidegger, reveló la influencia de Suárez con su propio enfoque postmoderno del Ser, puesto que acepta que: "la concepción del ser de Suárez, y la interpretación que hace de sus predecesores, es lo más apropiado para realizar la exposición fenomenológica del problema"19. De modo que, en la generación de los estudiosos de fines del siglo XX, en base a lo que Schopenhauer, Heidegger y Gilson habían estimado en Suárez, se revivió el interés por su pensamiento. En tanto y como punto de partida, Jean-Fracois Courtine, analizó el método "histórico-sistemático" de exposición en las Disputaciones metafísicas en su libro Suarez et le système de la métaphysique ${ }^{20}$.

Por otra parte, en la reciente investigación de Valerio R. Lozano ${ }^{21}$, se demostró que el modo de exposición sistemático -de "historiador" de ideas filosóficas y de "apropiación del pasado a través del comprender de raíz" de Suárez-, había sido explícitamente referido, ya antes de Heidegger, en el siglo XVIII, por el filólogo y filósofo alemán Dietrich Tiedemann (1748-1803). Lozano argumenta con asombro que Tiedemann es la fuente principal de Hegel para la elaboración que hace éste del escolasticismo, con presencia/ ausencia de Suárez, en sus Vorlesungen über die Geschichte der Philosophie (Berlín, K. L. Michelet ed. 1833 - 1836). Ya que en esas lecciones de Hegel se hacía una sola referencia, indirecta, (a la Disputación I sección 6), que Tiedemann comenta en su obra Geist der spekulativen Philosophie (Marburg, 1796). Es aquí donde Tiedemann reconoce que

\footnotetext{
${ }^{18}$ Heidegger, (FCM), 51.

${ }^{19}$ Heidegger, $(P F F), 130$.

${ }^{20} \mathrm{Cf}$. Courtine, (SSM), 204-5.

${ }^{21}$ Valerio R. Lozano, "L’eredità nascosta di Suárez nel sistema hegeliano" in Francisco Suárez And His Legacy. The Impact of Suarezian Metaphysics And Epistemology On Modern Philosophy, ed. Marco Sgarbi (Milano: Vita e pensiero, 2010), 247. (Hereafter, $S \& H$ ).
} 
efectivamente: "Suárez ha leído la opinión de sus predecesores, y con reflexión aguda y profunda las ha comparado entre ellas, y a partir de esto ha extraído, en muchísimos puntos, luces nuevas, nuevas determinaciones y nuevos principios"22. Estos términos descriptivos se asemejan notablemente a los que utiliza Heidegger para darle su especial connotación fenomenológica a la concepción del ser de Suárez (Die Gundprobleme der Phänomenologie).

Por lo tanto, Tiedemann, admirador de la metafísica de Wolff, es el puente más importante para establecer la conexión filosófica entre Suárez y Hegel, o entre Suárez y la tradición alemana, y que Heidegger había vislumbrado en la perspectiva modernizante de Suárez. El método de apropiación positiva de las tradiciones antiguas es lo que permite a Suárez alcanzar su original punto de partida que, como un nuevo rumbo, tiene como consecuencia una perturbación histórica que se denominará modernidad, que en materia de enseñanza filosófica se consideró como "novedades peligrosas"23. Pero ¿Hacia dónde apuntan las novedades y por qué fue un innovador de ideas filosóficas? Pasaremos entonces a referir algunas de ellas en materias de: ontología, epistemología y psicología moral. Por último, se bosquejan materias de la praxis política de Suárez.

Ontología trascendental.- En su inflexión del significado entre el ser en cuanto tal y quien lo piensa ${ }^{24}$, Suárez elabora una nueva orientación para la ontología trascendental. Su enfoque -ya no es el de Aristóteles y Sto. Tomás de Aquino, como el ser sin más-; sino la razón de ese ser (ratio

\footnotetext{
${ }^{22}$ Lozano, $(S \& H), 248$.

${ }^{23}$ Valerio Cordeiro, O Padre Francisco Suárez (Porto: Ed. Magalhães \& Moniz, 1918), 1516; Francisco Suárez, De Legibus ac Deo Legislatore. Libro I Da lei en geral, eds. Mendo Castro, José A. Maltez, Artur Morão, Gonçalo Pistacchini Moita (Lisboa: Tribuna da História, 2004), 59. (Hereafter, Libro I Da lei).

${ }^{24}$ Francisco Suárez, Commentaria una cum Questionibus in Libros Aristotelis de Anima, vol. I-III, Trads. C. Baciero y L. Baciero (Madrid: Editorial Labor, 1971-1991) (Hereafter DA). En el $(D A)$, afirma "de una manera, el ente es objeto de la metafísica y, de otra, lo es del entendimiento. El ente es objeto del entendimiento en cuanto lo abarca todo (no es abstracción) y en cuanto cognoscible (DA IX 1). Estos textos en conjunto hacen evidente que para Suárez la línea divisoria entre metafísica y epistemología se hizo tenue.
} 
entis); el pensamiento de aquel ser, donde procurará hallar su razón esencial $^{25}$. El objeto de la metafísica, propone Suárez, buscando una salida al problema de la unidad del ser, es en el ser como tal, pero a este ser en cuanto tal se le imprime precisamente una suerte de inflexión refleja, la de: "concepto originario de cualquier ente real" 26 . Y de esto "Hay que decir, por tanto, que el ente, en cuanto ente real, es el objeto adecuado de la metafísica" 27 . Es este ser real, posible y pensable: el "a priori ontológico [que] sustituirá, en lo sucesivo, la trascendencia óntica del [ens] primum de la metafísica anterior" 28 . En tal a priori ontológico, por consiguiente, se jugaría en lo sucesivo la posibilidad de la metafísica como ciencia.

Los intérpretes de finales del siglo XX han discutido sobre el doble carácter del concepto de ser en Suárez, entre ellos: M. Höenen, L. Honnefelder, R. Darge, N. Wells, J. Doyle, J. Gracia, P. Aubenque, J. L. Marion, J. F. Courtine, J. P. Coujou, O. Boulnois, F. Volpi, C. Esposito. Es decir, sobre la dialéctica entre el concepto formal y el concepto objetivo. Por

${ }^{25}$ La caracterización general que hace de la metafísica es de ciencia especulativa- teórica, a priori y perfecta, porque se detiene en el conocimiento de la verdad por sí misma; teórica, porque emplea al intelecto especulativo en vez de práctico en el escrutinio de su objeto; perfecta, porque no le falta ninguna condición para demostrar científicamente las propiedades de su objeto; $a$ priori, porque se apoya en la luz natural del intelecto para alcanzar una cognición abstracta de las propiedades trascendentales de su objeto de estudio. (Suárez, Disputationes Metaphysicae, Trads. S. Rábade, S. Caballero y A. Puigcerver, (Madrid: Gredos, 1960-1967), I 2 1. (Hereafter, $D M)$. En seguida, advierte que siendo ciencia en sí misma, la metafísica no es independiente de la mente, "se halla solamente en nosotros", abarca toda la realidad, pero según la capacidad de nuestra inteligencia, según distinciones que ella pueda hacer. No es solo ciencia del ser, sino el procedimiento con el que se elabora la misma ciencia. (DM I 5 29, 39; 2 Proemio)

${ }^{26}$ Suárez, DM II 414.

${ }^{27}$ Suárez, DM I 126.

${ }^{28}$ Piere Aubenque, "Suarez et l'avénement du concept d'etrê", in Francisco Suárez (15481617). Tradição et Modernidade, eds. Adelino Cardoso, Antonio Martins, Leonel Ribeiro dos Santos (Lisboa: Ed. Colibrí, Centro de Filosofia da Universidade de Lisboa, 1988), 19 (Hereafter, Suarez et l'avénement). Esto quiere decir que Dios pierde el status que le dieron Aristóteles y Tomás de Aquino, "de a prioridad epistemológica", no es objeto adecuado de la metafísica, aunque conserva con Suárez, su eminencia de primero y principal. Aristóteles postulaba físicamente que la causa de la unidad de los diversos sentidos del ser era una sustancia separada inmóvil, necesaria, Tomás de Aquino, siguiendo a Aristóteles, interpretaba que es Dios trascendente, cuya relación con el ente creado se realiza por analogía de proporcionalidad. 
el primero, el entendimiento realiza el acto de concebir el objeto; por el segundo, el entendimiento se representa, a través del concepto formal, el objeto conocido. Pero Suárez mismo indicó una dificultad al respecto ${ }^{29}$ : por una parte, el concepto objetivo depende del concepto formal y, por otra parte, el concepto formal recibe su unidad del concepto objetivo. Por lo cual, Aubenque $^{30}$ y Marion ${ }^{31}$ reclamaron una "apariencia de circularidad" en la argumentación de Suárez, lo que invalidaría la prueba del acceso al ser. Sin embargo, a la objeción se respondió, que la aparente circularidad residía en determinar en qué consiste esa dependencia: pues esa relación se da en términos de fundamento (ratio essendi) y de conocimiento (ratio cognoscendi) entre el concepto formal y el concepto objetivo; los que se expresan en dos momentos, uno empírico y otro trascendental, que articula en su ontología ${ }^{32}$.

\footnotetext{
29 “Así pues, el fin principal de la Disputación II es explicar el concepto objetivo de ente en cuanto tal, según toda su abstracción, a la que debe, según dijimos, ser el objeto de la metafísica. Pero atendiendo a la dificultad del tema y a su íntima dependencia de nuestro modo de concebir, comenzamos por el concepto formal [...]" (DM II 11$)$.

${ }^{30}$ Aubenque, (Suarez et l'avénement), 15.

${ }^{31}$ Jean-Luc Marion, Sur le prisme métaphysique de Descartes, (Paris: PUF, 1986), 54.

${ }^{32}$ Giannina Burlando, "Suarez and Heidegger on the transcendental moment in the cognition trascendentalis", in New Essays on Metaphysics as Scientia Transcendens, ed. Roberto Pich (Louvain: Louvain-la-Neuve, 2007), 343-362.
} 
La reconstrucción del momento empírico ${ }^{33}$ y del momento trascendental ${ }^{34}$, fue explicada en detalle por Söchting ${ }^{35}$ (2007; 2014), quien demostró que Suárez pasa a establecer qué tipo de relación existe entre esos dos momentos argumentativos. En realidad, Suárez afirma que existe cierta prioridad parcial de la condición trascendental sobre la condición empírica en cuanto a la unidad objetiva del concepto de ser. Esta prioridad característica, propia de los argumentos de la razón, no es meramente metodológica, sino lógica y esencial: el intelecto es capaz de percibir en la audición de la palabra 'ser' y concebir su concepto formal, pues la razón es previa y a priori capaz de fundamentar las condiciones trascendentales (el ser real como objeto) mediante las cuales esa percepción y esa concepción empírica encuentran su unidad.

Tal análisis reveló que: (i) La salida de Suárez es ontológica y trascendental más que empírica, analógica y trascendente, como la

\footnotetext{
${ }^{33}$ Suarez adds "[...] because what is conceived is perceived with the mind, being thus subject to experience; now then, hearing the term being, and accurately conceiving what we understand it is meant by that voice, we do not perceive with our mind either the substance as such, nor the accident as such, depending on what everyone can experience in himself" (DM II 2 9). Besides, preferring audition upon vision, Suarez continues arguing: "the ways of acquiring science are learning and researching. In order to learn the ear is very useful, since voices are the concepts's signs and the ear is the only sense that perceives voices, and although it is not he who perceives the significations, but the mind, it is enough for it to be the proper organ through which the sign arrives to the mind. [...] the written word is also a sign of the concepts, and it is perceived by vision, from which it appears to be learnt much more things through reading. But anyway, there is a difference, that its almost completely utility of writing also that can be perceived by ear, but not the other way around, because of the energy, firmness, and distinctness which are in the voice to express the concepts of its own, cannot be supplied with the sole writing or vision" (Suárez, DM I 6 11).

${ }^{34}$ Suárez exclaims: "At last, from reality itself, and following some sort of a priori argument, it is demonstrated [...] that all real entities truly have some sort of resemblance and convenience in the reason of being, so, they can be conceived of and represented just under that very reason through which they convene among each other; therefore, under such a reason, they can account for one single objective concept, and thus, this is the objective concept of being" (Suárez, DM II 2 14).

35 Julio Söchting, "Perfecto En Humanidad: El Misterio De La Encarnación Como Problema Ontológico En La Disputationes Metaphysicae De Francisco Suárez S. J.” (Facultad de Teología, Pontificia Universidad Católica de Chile, 2007). Julio Söchting, Metafísica, (Santiago: Ediciones U. Católica de Chile, 2014) (Hereafter, Metaf.).
} 
elaborada por sus predecesores escolásticos, porque Suárez explica la razón de unidad y conveniencia en la articulación trascendental entre el momento empírico y el momento trascendental del concepto de ser. De hecho, (ii) Suárez relacionó el momento empírico con el momento trascendental. Existiendo una conexión mutua entre la experiencia y la intuición del concepto de ser en su constitución a priori. El pasaje crucial decía: “[...] porque, aunque el concepto formal, producido en nosotros por nosotros mismos, puede parecer más conocido por la experiencia, sin embargo, la comprensión exacta de su unidad depende en gran medida (multum pendet) de la unidad del objeto, de la cual los actos reciben frecuentemente su unidad y distinción" 36 .

La relevancia de este pasaje es que, interconecta la experiencia cognitiva a posteriori de la unidad del concepto formal, y la comprensión a priori de esa unidad, que depende en gran medida de la unidad del objeto, es decir, de la unidad del concepto objetivo probado por el segundo argumento de razón (n. 11). Así (iii) se mostró una salida a la apariencia de circularidad al señalar la articulación del momento empírico y trascendental, en la constitución del concepto objetivo del ser. Esto, nuevamente, es posible debido a la relación intrínseca entre el concepto formal y el objetivo, como uno de fundamento (ratio essendi) y uno de conocimiento (ratio cognoscendi).

Suárez es claro sobre la prioridad parcial del argumento de razón sobre el argumento de experiencia, porque el problema de la unidad del ser se resuelve en primer lugar en el acto así como en el contenido de nuestro pensamiento sobre el ser; sin embargo, el acceso a los términos del ser, la prueba a priori es siempre a través de la experiencia que es su salida, el acto de concepción -o el concepto formal. Aquí cabe señalar que la misma

\footnotetext{
36 “"nam, licet formalis, quatenus a nobis et in nobis fit, videatur esse posse experiential notior, tamen exacta cognition unitatis eius multum pendet ex unitate obiecti, a quo solent actus suam unitatem et distinctionem sumere" (Suárez, DM II 1 9). According to Courtine, from this passage of Suarez's metaphysics arises "son secret déséquilibre, faire éclater la tension même qui la constitue, et qui est destinée se résoudre [...] en la métaphysique générale comme ontologie" (Courtine, "Le projet suarezien de la métaphysique", Archives de philosophie 42, (1979): 235-36. (Hereafter, Le projet suarezien)
} 
concepción del ser es objeto de una determinada percepción que no es la percepción de seres particulares, sino una percepción que se refiere a la relación entre la palabra y el concepto, como se citó en el primer argumento de experiencia: "cuando la mente se familiariza con la palabra ser, también se retrae en un solo concepto" (nota 10). De hecho, como se defendió en la secuencia relativa a la articulación de ambos tipos de argumentos, que existe coherencia entre la ratio essendi -que es una cognitio trascendentalis- y la ratio cognoscendi -que es una notitia empirica. La mente es capaz de captar al oír la palabra como concepto formal, porque previa y a priori, la razón es capaz de establecer las condiciones trascendentales -el ser real como objetopor las que esa percepción y concepción empírica encuentran su unidad trascendental. Este es, pues, el nuevo comienzo de la metafísica: desde la scientia trascendens a la cognitio trascendentalis. El giro trascendental proporcionado por Suárez recae sobre un acto de la mente, su capacidad para realizar una abstracción trascendental metafísica y para concebir el término de esa abstracción, también el objeto.

En adelante, se verá, que esto es lo que involucra un antecedente fenomenológico en la ontología suareziana como lo ven Heidegger, Volpi o Courtine. La articulación de estos dos momentos argumentativos, es una clara señal respecto a la orientación trascendental moderna en la interpretación del problema del ser y de la ontología en Suárez. En este sentido: "Es especialmente fecundo considerar que la orientación trascendental que se advierte en la prioridad trascendental parcial, de los argumentos de razón respecto de los argumentos de experiencia, contiene una superación de Kant, pues separa la experiencia de la estructura trascendental de la razón e, incluso, una superación de Husserl, dado que intenta abrir la trascendentalidad de Kant en la intencionalidad de la consciencia. Esta superación se detecta en el momento empírico de la percepción y la concepción del ser en el concepto formal y su articulación trascendental en la unidad del concepto objetivo" 37 . Esta doctrina entonces, bien puede considerarse un antecedente fenomenológico y por tanto, un

\footnotetext{
${ }^{37}$ Söchting, (Metaf.), 301.
} 
antecedente de la filosofía moderna respecto de la pregunta que interroga por el sentido del ser en Heidegger: la comprensión del ser como constitutivo existencial del Dasein es, precisamente, percepción "trascendental" del ser, según el análisis de Söchting.

Epistemología y lenguaje mental.- De modo que, ante las advertencias de Heidegger, Zubiri, Courtine y otros con respecto a la influencia de las doctrinas de Suárez en la filosofía de la Edad Moderna, incluso determinando los fundamentos y metas de la lógica de Hegel, se agregan otras, todavía más explícitas y reconocidas hoy en día. Pues, en el caso de Hegel, como ha mostrado Lozano, hay una influyente traducción del léxico de Suárez, al menos en sus categorías de 'ontología', 'concepto', y 'posibilidad'. En cuanto al "concepto objetivo, se pone como base y condición de posibilidad de la actividad formal de la mente. En eso consiste la gran innovación hegeliana del begriffendes Denken"38. "El pensamiento concipiente y el pensar formal, no como un simple acto de mi mente, sino como una producción del término objetivo: el objetivo resulta del formal [...] Por esto, concebir, para Hegel, no es simplemente un acto formal del sujeto, y ni siquiera una creación ex nihilo de las cosas; concebir es la actividad del concepto mismo. Se trata no del hecho que un sujeto posea la actividad de concebir, sino del hecho que el concepto, tomado unitariamente, es en sí mismo una cosa viva, cuya actividad es precisamente concebir (das begriffendes Denken)"39. De modo que la "dicotomía suareciana, entre el concepto formal y objetivo, daría lugar en el pensamiento de Hegel, al sich rundendes Denken, a la circularidad autoproductiva del concepto" ${ }^{40}$. Esta auto-producción del concepto constituye una parte del pensamiento epistemológico de Suárez, puesto que se incluye en su discusión de la función creativa e inventiva del Ars de las ideas

\footnotetext{
${ }^{38}$ Lozano, $(S \& H)$, 253. (My transl.)

39 Xavier Zubiri, Los Problemas Fundamentales De La Metafísica Occidental, (Madrid: Alianza Ed. 1995), 258. (Hereafter, PFMO)

${ }^{40}$ Lozano, $(S \& H), 253$.
} 
divinas ${ }^{41}$, con las cuales guardan una proporción los "conceptos formales" -subjetivamente presentes en el intelecto humano-, en cuanto a su modo de existencia, representación y causalidad ${ }^{42}$. Suárez sostiene efectivamente que “conocer la idea sirve para producir"43. Así es que: "Las ideas están en Dios intrínseca y formalmente, en cuanto que es inteligente y en cuanto representa intelectualmente todas las cosas" ${ }^{4}$; lo cual quiere decir, que están en función del concepto o del acto del entendimiento divino ${ }^{45}$. La idea entonces es equivalente al concepto formal, y no al concepto objetivo -ya que ese es el modo humano de terminar la actividad cognitiva ${ }^{46}$, y que cumple, para Suárez, funciones de: 'guía de la acción del agente hacia un término y un fin cierto', 'regla de verdad' y 'principio formal del conocimiento' ${ }^{47}$. Para

${ }^{41}$ Para defender la causalidad eficiente de la idea, Suárez sostiene que "sed ars non causa nisi mediante idea; docet enim ars fabricari in mente tum rem efficiendam, tum etiam viam et modum exsequendi illam, atque in hunc modum est principium artificiosi effectus" (Suárez, DM XXV 2 12).

${ }^{42}$ Las de la mente humana son ideas menos perfectas: 'conceptos confusos', ya que "entran de por sí en la intención del agente" y este naturalmente es un "artífice imperfecto, o imperfectamente cognoscente" (Suárez, DM XXV 1 18).

43 “[...] cognitio ideae ad causalitatem deserviat” (Suárez, DM XXV 135 ).

${ }^{44}$ Suárez, DM XXV 126.

${ }^{45}$ For Suarez formal concepts o 'intentional representations' also belong to the exemplars or ideas's identity. Thus, he claims, "Ideae, procet in Deo sunt, non concurrunt ad cognitionem creaturum per modum objecti proximi, sed per modum actus intellectualis quo intentionaliter representantur creature ipsae [...]"' (OTS I IV 8).

${ }^{46}$ Esta es opinión defendida ya sea por D. Scoto, Ockham, Gabriel, el Aliacense, Durando, Bassolis, y Sto. Tomás, o los tomistas, quienes suponen que el ejemplar posee razón de objeto conocido ('rationem obiecti cogniti'), es decir, significa la cosa conocida (DM XXV 1 6-7).

${ }^{47}$ Suarez describes divine ideas as follows: (1) They guide the intellectual agent's action so they can point out (tendat) to a certain end (2) this pointing out or direction is accomplished by an actual representation of the mind, which is a kind of light that precedes showing the way, and terminus of the operation (all this is done formally by the same formal concept of the mind); (3) are measure or rule of truth, and a property of the thing done; (4) are principles of knowledge, or the same formal concepts are principles of knowledge, and not the objects as they are known, because this object as it is known is the end and terminus of knowledge (DM XXV I 29) (my italics). In this account, Suarez not only follows Aquinas's basis at De Verit. I 15, but frequently to Augustine at Soliloquio II 5, De Vera Religione 36, for conceptions of 'true divine idea', 'truth', and mental language in particular (Cf. Suárez, DM VIII 5 5; 7 2; 7 21; 7 34). 
Hegel, "no solo el objeto viene producido, sino que se identifica a su vez con el concepto mismo. El término final [del desarrollo del concepto] es precisamente el concepto que se sabe el mismo, en modo adecuado, ser aquella identidad. El concepto que sabe de este modo es precisamente lo que Hegel llama idea" ${ }^{48}$. En las interpretaciones de Zubiri y Lozano, la idea absoluta hegeliana se explica recurriendo a Suárez; pues en Suárez "conocer todas las cosas, posibles y reales, a través de un solo concepto formal, es exclusiva facultad de la divinidad. Y exactamente esto es la razón absoluta de Hegel. La idea de Hegel es la razón que se sabe a sí misma como acto formal concipiente de la realidad de sí misma y de las cosas"49.

Por otra parte, la orientación trascendental de la metafísica Suárez y su enfoque conceptual (Conceptual Focusing), cuya principal función es "resolver la aparente antinomia entre el carácter diádico y unitario del ser" (Pereira, 2014: p. 308), culmina en una fase idealista moderna (Pereira, 2014: p. 312), "a mentalist turn that recent scholars have both applauded and lamented (depending on their stance toward modernity" (Schloesser, 2016: 93). Tal giro, como veremos, implica una nueva teoría semántica. Ahora bien, con respecto al lenguaje mental, Suárez introdujo modificaciones frente a las perspectivas medievales de Walter Burleigh, William Ockham y Jean Buridan. Para esto se apoyó en la tradición de San Agustín, San Buenaventura y Capreolo, orientada a la subjetivación de la idea. En tanto como ha demostrado Ranemann, el conocimiento de Dios y la intelección de los seres humanos están interconectados (2014: p. 329), y Suárez está convencido de que los auténticos términos de la scientia divina y de la cognición humana, son ideas o conceptos.

El lugar central que Suárez da a los conceptos simples como capaces de verdad trae consigo una deconstrucción de las posiciones tradicionales sostenidas por Aristóteles y Tomás de Aquino, por lo que puede verse como una innovación en la epistemología moderna, con especial influencia en

\footnotetext{
${ }^{48}$ Zubiri, (PFMO), 293.

${ }^{49}$ Zubiri, (PFMO). 293; Lozano, (S\&H), 254.
} 
Descartes $^{50}$. Según el análisis de Suárez, los conceptos adquirieron el estatus cualitativo de ser real inteligible. Para el jesuíta, los conceptos tenían una relación diádica de significado/representación con las palabras (convencional, mediato) y con las cosas (inmediato, natural). El fenómeno de la verdad objetiva no se produce en palabras oracionales, ya que las palabras eran consideradas solo signos analógicos de conceptos, sino más bien en el lenguaje del concepto. Puesto que, los conceptos intencionalmente representados, señalan e incluso arrastran cosas (vera tendentia at rei) al acto de conocimiento de la mente ${ }^{51}$. Así, Suárez hace que los conceptos jueguen un rol paradigmático en la semántica de la significación y la verdad. De hecho, los conceptos fueron considerados por Suárez como términos mentales reales, el significatum de palabras y proposiciones: lo que significan; lo que se concibe mediante palabras habladas; lo que tenía valores semánticos: son verdaderos o (metafóricamente) falsos; lo que se conoce; lo que se percibe solo con la mente; aquello que capta la mente; aquello que informa al intelecto; lo que es traslúcido, distincte et clare o confuso para un sujeto ${ }^{52}$; aquello que es prejuicioso captado por la mente; aquello de lo que dependen los juicios; lo que se expresa con palabras; lo que significa y connota otros: cosas, objetos o conceptos; lo que es útil para la producción. La doctrina del lenguaje mental de Suárez reveló su

\footnotetext{
${ }^{50}$ The central place for truth in Descartes, like in Suárez, is the same cognitive order, though predicative truth implies the pre-predicative truth of the idea. In other words, it may be said that predicative truth depends on the pre-predicative truth of the idea, and not the other way around. En la Meditación III busca un criterio general para el conocimiento y lo encuentra en esa regla general ("So I now seem to be able to lay it down as a general rule that whatever I perceive very clearly and distinctly is true." (illud quod omne este rerum quod clare et distincte percipio), Descartes, Meditations on First Philosophy, Meditation III, in Philosophical Writings of Descartes, Transl. John Cottingham, Robert Stoothoff, Dugald Murdoch, vol. II (New York: Cambridge University Press, 1984), 249), realizando una transferencia cognitiva; pues en el pasaje citado ha trasladado el lugar de la verdad; la cual ya no está más en la conformación entre cosas y juicios, ni entre cosas y palabras; puesto que el criterio cartesiano de verdad, ahora, depende absolutamente de las ideas, son pues las ideas pre-judicativas el nuevo lugar de la verdad, si poseen claridad y distinción.

${ }^{51}$ Suárez, DM VIII 42.

${ }^{52}$ Suárez, DM VIII 318.
} 
conciencia de las diversas preocupaciones epistemológicas, lógicas y semánticas de la filosofía moderna. Por otro lado, lo genuino de la doctrina de Suárez sobre la verdad equivale a: (i) el lugar donde transfirió la denominada significación primaeva de la "verdad", y (ii) el tipo de expresión lógica que usó para designar también la verdad ontológica. Suárez situó la verdad en los conceptos mentales. Para evitar la mera certeza psicológica derivada de simples aprehensiones. Suárez mantuvo el concepto de distinción formal/objetiva, y le agregó cognición in actus exercitus. Por lo tanto, al combinar el carácter intencional/representativo/significante de los conceptos con su carácter reflexivo para alcanzar otros conceptos, se debía preservar la objetividad de la verdad. De hecho, el lugar de la verdad transferido por Suárez a conceptos simples marcó una nueva dirección para las epistemologías modernas ${ }^{53}$.

Psicología filosófica.- Sobre la psicología filosófica, la modernidad de Suárez se revela en su teoría empirista de la simpatía. Ésta sustituye en su momento, la brecha que había dejado la explicación causal del aristotelismo escolástico. Se provee de un fundamento metafísico para la conexión entre los poderes y la actividad vital del alma en los seres vivos, y constituye el gozne sobre el cual Descartes articuló su concepto de mente. Como Descartes, Suárez rechazó un mecanismo transductor y enraizó los elementos cognitivos en una misma cosa: la facultad cognitiva integral, la res cogitans de Descartes. Ambos filósofos apelaron al método de la observación empírica y a la medicina galénica para explicar, por ejemplo, cómo el cerebro comunica su energía a los sentidos ${ }^{54}$.

Psicología moral.- Otras señales de modernidad filosófica se pueden determinar en su psicología moral. Se evidencia en esta doctrina una trasferencia esquemática desde el Tratado De passionibus et habitibus (1620) y la Disputación XLIV de las Disputaciones Metafísisicas de Suárez,

\footnotetext{
${ }^{53}$ Burlando, "Suárez on Translatio vocis 'veritas", in Suárez's Metaphysics in its Historical and Systematic Context, ed. Lukáš Novák (Berlin/Boston: De Gruyter, 2014), 77-8.

${ }^{54}$ Suárez, DA VI 6. Cf. Burlando, "La Arquitectura Mental en el Escolasticismo", Revista de Filosofía, vol. XLV- XLVI, (1995): 100, 115.
} 
$a$ la Meditación IV de las Meditaciones Metafísicas y Les Passions de l'Âme de Descartes. Aunque Suárez presupone que las pasiones no intervienen necesariamente en el ejercicio de la voluntad, las denomina afectos del alma (affectibus animae seu passionibus), y las aborda en conjunto con los hábitos buenos o virtudes para teorizar precisamente sobre "pasiones que versan sobre virtudes" 55 . Las doctrinas de lo que hemos llamado psicología moral de Suárez y Descartes incluyen centralmente una revisión de la relación entre las pasiones, la voluntad, y la virtud. El modo en que ambos explican dicha relación, se enmarca dentro de una concepción general de la relación mente-cuerpo y de las funciones que corresponden a las facultades mentales que, finalmente, aparecen siguiendo las tendencias internalistas del siglo XVII, pero, en cada caso, demarcadas por un conocimiento biológicovitalista, à la Suárez, o un conocimiento médico psico-fisiológico, à la Descartes. Ambos pensadores estuvieron convencidos de la imposibilidad psicológica de la razón para refrenar las pasiones y al mismo tiempo, buscaron un sistema para adaptarlas y usarlas para el fortalecimiento del pensamiento y la conducta que resulta favorable a la vida. La esfera psicológica adecuada, parece situarse en los confines de la razón, es decir, en el más allá de una voluntad que se puede perfeccionar mediante los hábitos afectivos. La fuerza del impulso libre de la voluntad, la repetición, los ejercicios del espíritu y la práctica sostenida de la virtud, constituyeron para Suárez y Descartes un sistema interno de auto regulación consciente, en grado de minimizar los efectos de aquellos movimientos físicos involuntarios o no queridos ${ }^{56}$.

Lo anterior equivaldría a reconocer una nueva posibilidad de enfoque en la historia de la ética filosófica, que se distingue claramente del estoicismo ortodoxo. Puede considerarse como una corriente neo-estoica

\footnotetext{
55 Suárez, Tractatus Quartus De Actibus qui Vocantur Passiones tum etiam Habitibus, praesertim Studiosis, ac Vitiosis. Opera Omnia, vol. IV (París: ed. L. Vivès, 1856), I p. 455 (Hereafter, DP).

${ }^{56}$ Remo Bodei, Geometria delle passioni (Milano: Feltrinelli, 1992), 310.
} 
moderna, conocida como moral psicologizada, de acuerdo a John Rawls57, o como el giro emocional en la filosofía y la historia58. Las evidencias textuales muestran que Suárez puso en cuestión la antigua convicción de una sensualidad irracional y amoral, y en cambio, intentó trazar un sistema de simpatía de relaciones psicológicas, implicando un vínculo íntimo entre la moral y las pasiones humanas. Metodológicamente, Suárez había revisado las fuentes peripatéticas, neoplatónicas y galénicas, en virtud de lo cual dio inicio a una nueva ciencia ética, en términos de una vía media para considerar la pasión moderada como: 'virtud afectiva capaz de inclinarnos, sin defecto, a obrar con rectitud y honestidad' 59 .

\section{II}

Lo moral como dimensión propia del hombre: Filosofía y praxis política. En 1976 Patrick Riley anotaba que denominar el primer gran teórico contractualista a Hobbes, podía significar hacer «injustice to a writer such as Suárez» ${ }^{60}$, dado que efectivamente el tratado De legibus contiene, considera él, «a remarkably complete voluntarist and contractarian doctrine, which bases many private, public and even international obligations on promise and voluntary agreement ${ }^{61}$. Sucesivamente, varios intérpretes ${ }^{62}$, se dedicaron a demostrar que Suárez, en su rol de teólogo moral, adelantó la

\footnotetext{
57 John Rawls, Lectures on the History of Moral Philosophy (Harvard: Harvard University Press, 2000).

58 Simo Knuuttila, Emotions in Ancient and Medieval Philosophy (New York: Oxford University Press, 2004).

${ }^{59}$ Suárez, DM XLIV 13 14. Cf. Burlando, "Psicología moral en Suárez y Descartes: La pasión en la vida virtuosa", Anales de la Cátedra Francisco Suárez 51 (2017) (forthcoming).

${ }^{60}$ Patrick Riley, "Locke on "Voluntary Agreement" and Political Power", Political Research Quarterly, 29, (1976):138. (Hereafter, Locke on Voluntary Agreement)

${ }^{61}$ Riley (Locke on Voluntary Agreement): 138.

${ }^{62}$ Entre ellos, Cedroni, 1996; Calafate, 1999; Castro Henriques, 2004; Camacho, 2008; Doyle, 2010; Coujou, 2010, 2012, 2014; Pistacchini Moita, 2004, 2014 y otros.
} 
modernidad - treinta y nueve años antes de la publicación del Leviatan (1651) de Hobbes y setenta y siete años antes de la aparición de Los Dos tratados de Gobierno (1689) de Locke- defendiendo la doctrina de un pacto contractualista, con bases en obligaciones privadas, públicas e incluso internacionales, acordadas voluntariamente, dentro una sociedad comunitaria que, decisiva y pragmáticamente, se ordena a sí misma bajo el primado de la ley civil ${ }^{63}$.

Los tratados De legibus y De defensio fidei continúan hasta hoy siendo objeto de interpretaciones entre filósofos, politólogos e historiadores contemporáneos, puesto que allí se formulan numerosas doctrinas políticas, tales como: el estado de naturaleza, el imperio del derecho y de la ley, la soberanía popular ante el derecho divino de los reyes; la legitimidad política por el consenso; las relaciones del poder, entre el poder espiritual y el poder temporal, la democracia como alternativa a las monarquías absolutas; el derecho a la resistencia y la rebelión popular contra el mal gobernante y rey tirano; la ilegitimidad de la tiranía, la esclavitud comparativa, la coerción de la fe a indígenas o gentiles, el colonialismo, la ocupación de territorios, la libertad de culto, la libertad de consciencia religiosa, las virtudes cívicas, la libertad y la autonomía del individuo frente a los grupos impositivos del poder. Estos postulados éticos advierten de una historia viva y concreta, que se comprueba al incidir moral y políticamente en los hechos sociales de la época, entre ellos: (i) el doble proceso de secularización: la independencia de la Iglesia y el Estado, la política y la religión; (ii) el comienzo de la ley internacional; (iii) el legado de la controversia de Valladolid, sobre el estatuto de los indígenas de América. Este importante episodio también se relaciona con el reconocimiento de la Reforma por parte de la Iglesia Católica, iniciado ya en el Concilio de Trento (1545-1563); (iii) la búsqueda de la paz europea, dependiente de la amistad entre Inglaterra y España; (iv)

${ }^{63}$ Coujou, "Political Thought and Legal Theory in Suárez", in A Companion to Francisco Suárez, eds. Victor Salas, Robert Fastiggi (Leiden, Boston: Brill, 2014): 29-71. (Hereafter, Political Thought) 
el contrato de una humanidad universal ${ }^{64}$. A lo anterior se agrega que la influencia del pensamiento político de Suárez fue relevante en: (v) los hechos históricos conducentes a la independencia de Portugal y a la conformación de una república democrática en los imperios ibéricos ${ }^{65}$; (vi) el discurso independentista de México; (vii) la aparición privilegiada de pensadores libres respecto de la ideología institucional, capaces de pensar por sí mismos con ingenio creativo y que ejercieron contrapoder desde la literatura y la cátedra, como el caso emblemático de sor Juana de Inés de la $\mathrm{Cruz}^{66}$, ya que representa a las minorías de su época, donde la mujer y la vida conventual, siendo un espacio separado del poder público y académico, irrumpe con la aparición de un pensamiento identitario novo-hispánico, que se opuso mediante su literatura a la administración colonial y sus excesos ${ }^{67}$. Por último, como efecto y alcance de interés, se puede constatar la práctica constante dentro de la orden jesuita del espíritu independiente y frontal de Miguel de Viñas, rector del colegio jesuita en Santiago de Chile (1699), quien impulsó el método de la disputa entre escuelas para combatir ("por la verdad, ganar y complacerse en ella") ${ }^{68}$. De modo que este tipo de

${ }^{64}$ Coujou, (Political Thought), 29-30.

${ }^{65}$ Los intérpretes lusos contemporáneos establecen una relación causal directa entre los postulados filosófico - políticos de Suárez y los hechos históricos conducentes a la independencia de Portugal y a la conformación de la república democrática en los imperios ibéricos. (Cf. Eds. Castro et al. (Libro I Da lei), 45.

66 “Autores como Pedro Abarca, S.J., Tractatus de voluntate Dei, Miguel de Castilla en Tractatus de divina Gratia, Antonio Figueroa Valdés en Tractaus de libero arbitrio, el propio confesor jesuita de sor Juana, Núñez de Miranda en su Tractatus de Scientia Dei, fueron intelectuales poblanos que estudiaron el tema de la libertad y de cómo, siendo ésta dogma de fe, suponía la participación activa del agente en cada uno de los actos humanos. He aquí el humanismo jesuita que siguió sor Juana" (Virginia Aspe, "La filosofía de Sor Juana Inés de la Cruz: cinco navegaciones filosóficas en el Primero Sueño y una propuesta heterodoxa", Universidad de Cuyo, Argentina (Abril, 2009):1-26.

${ }^{67} \mathrm{Cf}$. Aspe, "La imposición de la historia y las ideas filosóficas “oficiales" en México", Estudios 109, vol. xii, (verano 2014):16.

68"Siquidem ubi alter ex palestritis trumphali veritate laureatur; digladiator alius de victa falsitate triumphat"; o "Arrident vera, quia vera: displicent falsa, quia falsa" ("Puesto que, donde uno de los combatientes es coronado de laureles por la verdad triunfante, el otro adversario triunfa sobre la falsedad vencida; se sonríen con lo verdadero, porque es verdadero, 
enunciación moral de principios en los escritos políticos de Suárez, se articulan también en tanto vectores históricos de hechos y acciones.

Sin embargo, algo nuevo en relación al Renacimiento, se vio aparecer en esta compleja trama de pensamiento y acción política. La política de trasfondo en los textos políticos de Suárez no consistió en la construcción de una rigurosa ciencia política o en la descripción de técnicas del arte de lo político; tampoco en "una ampliación de las bases sociales del Estado, ni de la envergadura espiritual de su conductor" ${ }^{69}$, asunto de lo cual discurrió tensa e incisivamente Maquiavelo en El Príncipe. De acuerdo a las necesidades nuevas de los tiempos, de la segunda etapa de Contrarreforma, lo que importó no era elaborar una narración sobre cómo "el Estado actúa, conquista y destruye sin tener que rendir cuentas a nadie, [y] constituye de por sí un valor supremo"70, sino, cómo se levantan las piedras angulares de un nuevo edificio jurídico político, que inaugurará un estilo comunicativo de menor violencia, como una práctica política de mediación diplomática de paz, que intenta conseguir acuerdos entre el Estado y la Iglesia. En las transacciones entre el reino y la curia pontificia, Suárez pone en práctica efectiva el método de los Consilia Moralia; pero a diferencia de Botero y Rivadeneyra $^{71}$, él teólogo jesuita reviste los consejos morales con el lenguaje normativo del derecho natural y aplica criterio jurídico horizontal. En vistas a tal fin, Suárez levanta su monumental edificio onto-político sobre las bases conceptuales de: el 'derecho natural', la 'ley humana', 'bien común', 'vida comunitaria', 'estado de naturaleza pura', 'poder del estado', 'poder moral', 'alteridad', 'unidad política', 'relaciones interindividuales', y la 'libertad humana'; cuyo entramado teórico sistemático "no solo conforma la comprensión del ser-en-común, sino que renuevan el pensamiento sobre el

\footnotetext{
se disgustan cono lo falso, porque es falso") (Miguel de Viñas, Philosophia Scholastica, Génova, 3 vols. (1709), 9. Cita en Roberto Marconi Juárez, "La idea de filosofía en Miguel de Viñas, S.I. en su contexto histórico-cultural". Tesis doctoral defendida el 19 de mayo de 2021).

${ }^{69}$ Federico Chabod, Escritos sobre Maquiavelo (México: FCE, 1984), 138. (Herafter, Escritos).

${ }^{70}$ Chabod, (Escritos), 29.

${ }^{71}$ Giuseppe Toffanin, Machiavelli e il tacitismo: la politica storica al tempo della controriforma (Padova: A. Draghi, 1921), 92.
} 
ser-individual y, a su vez, completan la comprensión del modo de ser del Ser"72. Asimismo, la escritura legalista de Suárez en sus documentos epistolares de la época ${ }^{73}$, es signo de su propio ejercicio de jurisprudencia; donde delimita el poder político y los deberes del príncipe, quien está obligado a cumplir sus compromisos con los súbditos. Porque es deber del rey someterse a la ley y defender a sus vasallos oprimidos. Muchas de las palabras y enunciados en lengua portuguesa o española, usados en Conselhos e pareceres, no son para describir meramente estados de cosas, sino para trasmitir e imponer una idea ética de lo que debe ser la acción política $^{74}$. De manera que estos escritos vienen a revelar nuevos cauces comunicacionales para establecer límites de la jurisprudencia, en la negociación y conciliación. El teórico político canónico del De legibus, de la Defensio fidei y de los escritos epistolares, defiende también que los derechos fundamentales de la persona son inviolables. Lo fundamental que se revela en sus obras políticas y su práctica diplomática es de una alta complejidad en el sistema y el desarrollo de las ideas protodemocráticas del suarismo, que no solo comprenden la interpretación técnica del derecho, de la ley y del gobierno, sino también las prácticas discursivas concretas del consejo moral inspiradas por el derecho natural y que influyeron efectivamente en conciencias de sujetos del poder, conduciendo a reafirmar un doble proceso de secularización: por un lado, independizar la Iglesia del Estado y la política de la religión, y por otro lado, desplazar la política a un ámbito público de mediación instrumental, en este caso, mediante reglas de juego que incluyeron la vía de la correspondencia diplomática con retórica eclesial y secular al mismo tiempo, junto con la aplicación de criterio jurídico horizontal manifiesto en el peso del derecho tanto canónico como civil. Tal forma de acción comunicativa se proyectó cultural y

\footnotetext{
72 Coujou, "La constitution suarézienne de l'unitée transccendentale et ses implications anthropologico-politiques", Revue philosophique de Louvain, (2010): 586.

${ }^{73}$ Suárez, Conselhos e pareceres (Coímbra: Acta Universitatis Conimbrigensis, 1948-52). (Hereafter, Conselhos)

${ }^{74}$ Suárez, (Conselhos), I 56, 58, 59, 60.
} 
crecientemente en los procesos democráticos de la modernidad, configurando particularmente el nacimiento del Estado moderno.

Antropología.- Sin embargo, para llegar a comprender tanto la filosofía como los alcances de la praxis política moderna en Suárez, es necesario remontarse hasta su germen, lo cual quiere decir, la antropología teológica que Suárez adscribe, raíz profunda de su meditación moral, que él considera como el ámbito propiamente humano ${ }^{75}$. En esta dirección, Paul Pace, S. J., analiza el tema culminante del De legibus, es decir, la ley natural, con el propósito de extraer sus más valiosas consecuencias. Pace se propone demostrar que "a pesar de que [Suárez] escribió en un mundo tan diferente del nuestro, y en un estilo que parece inaccesible para el lector contemporáneo, su reflexión y, especialmente sus conclusiones, se muestran eminentemente relevantes para las mentes del siglo XXI"76. Por lo que no se queda en la mera crítica contemporánea interna a la teoría del derecho natural, es decir, en torno a si es la "naturaleza" o la "naturaleza racional humana", o bien la voluntad divina lo que funge como fundamento de las normas. Da por hecho que, para Suárez, la ley natural no está inmediatamente en la misma naturaleza, como lo expone en De legibus, (II, 5 12). Pace está de acuerdo con la interpretación de $\mathrm{Coujou}^{77}$, para quien lo que Suárez admite es un orden moral racional, o como lo expone Pistacchini, tal "moral [es] el lugar propiamente humano"78. Esto quiere decir que la ley y el derecho natural es producto de la razón y de la libertad humana, no de un orden preestablecido como el de la necesidad natural.

Con respecto a la libertad, efectivamente se erige como concepto núcleo del pensamiento de Suárez ${ }^{79}$. En su significado moral, se entiende:

\footnotetext{
${ }^{75}$ Pistacchini, (AMFS), 225.

${ }^{76}$ Paul Pace, S. J. "Suárez and the Natural Law”, in (ACTFS), 274.

${ }^{77}$ Coujou, Droit, anthropologie \& politique chez Suárez (Paris: Perpignan, Artège, 2012).

${ }^{78}$ Pistacchini, (AMFS), 226.

${ }^{79}$ Suárez modifica la semántica de sus predecesores escolásticos, destacando que la libertad metafísicamente entendida se trata de un poder (potentia) "tal que posee el mencionado poder (vim) y jurisdicción sobre su acto" (Suárez, DM XIX 5 4). Psicológicamente "es el dominio
} 
"como posibilidad radical de la naturaleza racional de abrirse al otro, sin la cual -sea a nivel de la esencia o de la existencia-, el hombre no se realiza. [Ya que] el ser humano se comprende, antes que todo, en cuanto iniciativa racional, que en sí mismo se encuentra, de un modo inmediato, con su principio (el intelecto); el hecho que la libre realización de sí mismo sólo ocurre mediante otro, el cual, es irreductible al yo (es decir, no es instrumentalizable); el sí mismo se conecta con un nosotros mediante el compromiso y es reconocido por nosotros como diferente y diferenciable. En verdad, es el otro que en los varios niveles de la existencia humana, apela a nuestra libertad y la transporta más allá de sí misma, en un proceso gradual

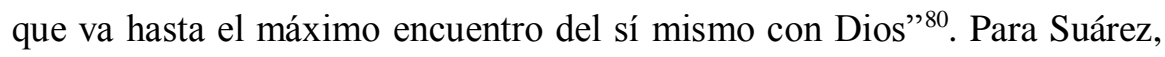
tal como argumenta Pistacchini, la autonomía y dignidad del ser humano, se defiende de un modo bastante diferente a la propuesta de otros reconocidos filósofos modernos, que olvidan el concurso del otro para existir. "En Suárez, de hecho, el hombre no se define esencial o existencialmente como un yo, antes se manifiesta siempre como un nosotros, puesto que el yo sólo existe en relación [...]. En cuanto a su esencia, la cuestión se pretende fundamentar primero con una definición de lo moral como lugar propiamente humano, a partir de que se comprende la libertad como principio de autonomía de la acción humana; y en segundo término, en la afirmación de una doble naturaleza del ser humano, (natural y sobrenatural),

\footnotetext{
sobre los actos propios" del agente (Suárez, DA XII 2). Pero precisa "es de esencia del poder libre, que por su intrínseca virtud y potestad pueda ejercer o suspender el acto" (Suárez, DA XII 2). De modo que de tal unión entre poder y acción, Suárez articula la libertad del individuo para que funcione en el nivel pragmático, en relación al otro y así quede vinculada a la teoría jurídica y política; esfera donde, por una parte, manifiesta supremo dominio, y por otra, conveniencia con el imperio de la ley natural. En el De finis homine, lugar donde expone su doctrina del hombre como ser moral, y de Dios como su fin último, insiste, por una parte, que la acción libre de los seres humanos es condición de su fin: la felicidad. Por otra parte, agrega que "la total naturaleza de la providencia divina está en el gobierno y dirección de los seres humanos a su fin." En la extensión de la providencia, el orden, las instituciones divinas y los medios por los cuales son dirigidos a su fin, Suárez incluye "a todas las criaturas de cierta manera", esta "cierta manera" es la "humanidad [por la que] todos ellos logran su felicidad". Así pues, desde la teología moral queda predefinido que todas las creaturas sean ordenadas a la salvación en tanto prosperidad de esa humanidad (salute humana) (Suárez, De fine homines).

${ }^{80}$ Pistacchini, (AMFS), 226.
} 
a partir de lo cual se comprende la libertad como principio de la dignidad del ser humano" $"$.

En el desarrollo de la antropología teológica expuesta en el $D e$ legibus, Suárez muestra su clara conciencia del conflicto entre autonomía y autoridad, entre libertad y poder político, pues formula la pregunta “¿existe un poder humano para obligar a otros hombres mediante la ley?" 82 a lo cual responde "hay que atender a la naturaleza humana que es libre"; sin embargo, en seguida admite: "la libertad individual es compatible con la sujeción, porque según la ley natural existen cosas ordenadas, prohibidas y cosas permitidas." Se ve aquí a Suárez discurrir vinculando razones ontológicas y morales para justificar la obligación, el deber político de todos los individuos a su gobierno. Argumenta que la ley es absolutamente necesaria a las criaturas racionales; primero, por su esencia intelectual, ellas son capaces del gobierno moral, lo cual se da por medio de la ley, y después, por su existencia, el hombre, que fue hecho de la nada, puede volverse hacia el bien o el mal, necesitando de la ley para poder escoger entre ellos. La ley, por tanto, al nivel de la existencia humana, impone una elección libre y racional entre el bien y el mal, al cual se llama propiamente obligación y cuyo lugar es la conciencia ${ }^{83}$.

Las razones morales son articuladas en términos de la teología; en base a que la teología católica es esencialmente soteriológica, es decir, su primordial objetivo no es teórico de deseo de sabiduría, sino pragmático en tanto quiere llevar las almas a la vida eterna, a Dios, su fin último ${ }^{84}$. En este

\footnotetext{
${ }^{81}$ Pistacchini, (AMFS), 226.

82 "Itaque quaestio est an homines, ex sola rei natura loquendo, possint imperare hominibus per propias leges eos obligando" F. Suárez, De legibus, Eds. Luciano Pereña y otros, 8 vols., Corpus Hispanorum de pace, 11-17, 21 y 22, (Madrid: C.S.I.C., 1971-81), III 11 (Hereafter, $D L)$.

${ }^{83}$ Suárez, DL I 12 5, en cita de Pistacchini (AMFS), 237.

${ }^{84}$ La causa formal de la teología es la dimensión de la gracia divina, pues, como explica Kuri Camacho: "la revelación y la fe teologal son gracias; asimismo la redención es una gracia y la fuente de todas las gracias con las que Dios socorre al hombre. Así que toda la revelación se ordena a la redención, como ésta a la salvación del hombre. A su vez, la obra de la salvación resulta del mérito sobrenatural al que la gracia eleva los actos humanos." (Kuri Camacho,
} 
sentido argumenta: "Dios debe ser considerado por el teólogo, más allá de muchos otros aspectos, también en aquel en que es el fin último para el cual tienden las criaturas que participan de razón, y en lo cual consiste su única felicidad" 85 . Además, como jesuita entiende que Dios se relaciona por amor con los hombres interviniendo en su historia. Así, agrega "Dios, en verdad, no es solamente el fin, y por así decir, la meta a la cual tienden las criaturas intelectuales, sino también quien establece el camino para alcanzarlo"86. La otra premisa teológica de Suárez es que la vía por la cual Dios conduce a los hombres es de índole moral, ya que los "ilumina con enseñanzas, los advierte con consejos y lo obliga con leyes; y sobre todo los ayuda con los auxilios de su gracia, por lo que justamente Isaías puede proclamar (32: 22) El Señor es nuestro legislador, el Señor es nuestro rey, Él nos salvará”. El énfasis de Suárez es que el camino de la salvación de los hombres radica en sus acciones libres y en la rectitud de sus costumbres. La gracia suficiente para la salvación viene exclusiva y directamente de Dios, quien se basta a sí mismo para salvar o condenar, pero esta suficiencia se acomoda a la cooperación de cada individuo, cuyo acto libre ayuda a que la gracia suficiente divina sea una gracia eficaz ${ }^{87}$. Este punto sobre la congruencia de los auxilios divinos y humanos, tiene gran importancia, pues quiere decir

\footnotetext{
"Francisco Suárez, teólogo y filósofo de la imaginación y la libertad", Revista de Filosofía, 58 (2008b): 88 .

${ }^{85}$ Suárez, (DL, Proemio), IX.

${ }^{86}$ Suárez, (DL, Proemio), IX.

${ }^{87}$ Suárez, Opusculum Secundum: De Scientia Quam Deus Habet De Futuris Contingentibus, vol. 11 Opera Omnia, (Paris: Ludovico Vivès, 1856-1878, L II 3 3), 553. (Hereafter, OTS). "[...] quomodo causa prima in efficiendo vel concurrendo se accommodet secundae, ut libertatem in ejus actionibus sevet. Sed utramque tractavi late in Metaphysica, disputatione 19, sectione tertia et quarta, et de secunda plura dixi in libris de Auxiliis" (Suárez, OTS I, 97333 ). Suárez dedica el Opúsculo Teológico Segundo al tema de la ciencia que Dios tiene de los futuros contingentes, incluyendo aquí la ciencia media o de la realización de los posibles. Este tratado pertenece a su Varia Opuscula Theologica (Madrid, 1599). Obra que aborda el tema de auxiliis desde los puntos cardinales de la teología jesuítica, i.e., (i) el concurso, moción y auxilio de Dios a la acción de las criaturas (tratado I); la Gracia o auxilio eficaz (tratado III); (ii) la libertad en Dios (tratado IV ); (iii) la reviviscencia de los méritos personales por el pecado mortal (tratado V); (iv) sobre la justicia divina (tratado VI).
} 
que "el ámbito moral no es necesariamente instaurado por Dios, ni es independiente de la libre colaboración de los hombres, por el contrario, resulta de un acto libre de Dios $y$ de los hombres. Del punto de vista de la esencia, la ley eterna depende absolutamente de un acto libre y creador de Dios, desde el punto de vista de la existencia, depende absolutamente del hombre, concretamente de que éste, una vez que ha sido físicamente creado, evoluciona como ser moral, proceso que no puede ocurrir sino a partir de su propia voluntad. La propia ley natural (al ser promulgada por Dios), surge en la consciencia de los hombres en tanto se constituyen moralmente, y esto sucede sólo a partir de un acto libre de sus propias voluntades" 88 . Dada esta estructura de la criatura racional, el hombre individual de Suárez se distingue ante todo por su 'intrínseca ordenación a otro'. Todos los hombres poseen una naturaleza ordenada a un fin último trascendente (bien absoluto) y moral, todos son iguales ante Dios y la ley, naturalmente dotados de razón, y todos son por naturaleza libres, no sujetos a otros semejantes. De lo cual se deriva que deban comprenderse también en una relación hacia fuera, dirigida concretamente a la alteridad social y política.

Filosofía política.- La doctrina política de Suárez, parte del supuesto que el hombre es una persona individual, pero como se vio, no concibe un yo puramente solipsista, un cogito, sum mental, anti social; "el cogito suareciano no es abstracto ni absoluto, sino concreto y relativo, fundándose esencialmente en el intelecto, pero existencialmente en la voluntad", potencia espiritual inclinada al hacer, que se somete al intelecto no despótica, sino políticamente, ya que puede desobedecer" ${ }^{\prime 9}$. Tampoco es un individuo psicológica y atómicamente clausurado en sí mismo, temeroso y egoísta, interesado en la pura protección a sus derechos privados, sino abierto a lo conveniente y comunicable con otros; por lo mismo, puede considerarse a este hombre como animal social que tiene el deseo natural de vivir en comunidad ${ }^{90}$.

\footnotetext{
${ }^{88}$ Pistacchini, (AMFS), 258.

${ }^{89}$ Suárez, DM V 4 2. (Cf. Pistacchini, (AMFS), 244).

${ }^{90}$ Suárez, DL III 13.
} 
La comunidad suarista no tiene un carácter débil e instrumental, sus individuos se unen a ella no para sacar ventajas particulares, sino buscando su crecimiento y felicidad integral. Es una comunidad políticamente organizada, fuerte en tanto funciona autárquicamente frente a otras comunidades, y sobre todo, lo que hace a su sistema de gobierno moral y jurídicamente legítimo, no es primariamente el acuerdo, tácito o hipotético entre los miembros de tal comunidad, sino la congruencia de las leyes del gobierno civil de la comunidad con el derecho natural y la justicia ${ }^{91}$.

La comunidad de Suárez, según anotamos, es diferente incluso del "Mitsein mit Anderen" elaborado postmodernamente por Heidegger. Sea esa expresión traducida como ser-con o como co-estar con los otros, en la que su significado apunta al 'con' o al 'com' de 'comunidad'. La descripción suarista de comunidad autárquica o perfecta no implica un 'con' o 'com' seco, neutro y separado de otros, en el que el individuo está proyectado en el mundo compartiendo apenas un lugar, a lo sumo un contacto: un mero estar-junto o, si se quiere, un estar-en-medio-de, frente, sin proximidad a los otros y, claramente, sin ensamblaje. En Suárez la vida en comunidad es consecuencia de la naturaleza no unidimensionalmente ontológica, sino también política del ser humano. El énfasis original de Suárez está en el tipo de ensamblaje entre el carácter del derecho, y el fin de la comunidad, un fin común y con alguna forma de jefatura, la cual tiende no a la felicidad futura de sus miembros, tampoco a la felicidad presente en toda su extensión posible, sino a la felicidad que deriva de la condición constitutiva de ser una comunidad/sociedad perfecta o suprema. Esto quiere decir no sujeta a otra

\footnotetext{
${ }^{91}$ Suárez, DL I 2 4. Según interpretación de Pistacchini, para Suárez hay ecuación entre el derecho (ius) y la ley en general. Aunque "se distingue entre derecho objetivo (que es naturalmente justo y equitativo y en este sentido igual a la ley) y el derecho subjetivo (que es lo justo legal, que concediendo a cada uno lo que es suyo, esto es, aplicando materialmente el derecho, puede hablar de lo que al contrario del derecho objetivo, no habla; el derecho subjetivo se distingue de la equidad, tiene como tarea atenuar la rigidez del derecho y descubrir su intención original (Suárez, DL I 2 10)" (Cf. Pistacchini, (AMFS), 235-6, 247; Courtine «La raison et l'empire de la loi», in Francisco Suárez (1548-1617) Tradição e Modernidade, eds. A. Cardoso, A. Martins, L. Ribeiro (Lisboa: Edições Colibri, 1998), 289-310.
} 
comunidad política de su misma esfera temporal -ella es su instancia última de conducción, legislación y jurisdicción- y se identificará con la potestad de régimen de la comunidad, que es política en sentido estricto, i.e., de la comunidad políticamente autárquica o autosuficiente en el orden temporal. A la vez los individuos, en tanto están ensamblados en esa comunidad por ley natural (ya que una vez reunida la comunidad de los hombres, opera la concesión divina de la ley natural), comparten en ella propósitos, obligaciones, responsabilidades y fines comunes. En suma, desde la perspectiva onto-teológica de Suárez, a los individuos los reúne un fin último trascendente; no obstante, eligen libremente no solo los medios, sino el fin último mismo, ya que pueden elegir amar a Dios o lo contrario. Si todos los hombres son por naturaleza libres y no sujetos a ningún otro, el gobierno (y en particular las leyes a las cuales se someten todos por igual) se justifica solo en cuanto necesario para la promoción y conservación del bien común.

A diferencia de Heidegger, en Suárez no hay dualismo radical entre individuo y comunidad, en la que el dasein es el único auténticamente trascendente ${ }^{92}$, el que se responsabiliza por llevar a cabo toda la tarea de un eigentliches Sein (o Ser auténtico), mientras que la comunidad humana es únicamente un receptáculo para ese dasein caído y pasajero. En Suárez la comunidad juega un papel dinámico de convivencia política, en el crecimiento moral de los individuos, quienes están relacionados tanto con los otros semejantes, como con la fuente suprema que trasciende su ser. La comunidad suarista no tiene un carácter débil, instrumental, ni impersonal, ya que sus individuos no se unen a ella para sacar ventajas particulares, sino buscando su desarrollo y felicidad integral. Los fines de la comunidad como tal tienen vínculos morales que garantizarán al individuo singular las condiciones de su buen vivir en toda su complejidad ${ }^{93}$. Esta comunidad que

\footnotetext{
92 Heidegger, $(P F F), 357$.

${ }^{93}$ El buen vivir, la felicidad, o el sumak kawsay de los otros, como se entiende en el mundo andino amazónico de Latinoamérica, se reconoce oriundo de ontologías relacionales que alcanzan su máxima expresión en el establecimiento de la Constitución ecuatoriana, en el derecho "de la población a vivir en un ambiente sano y ecológicamente equilibrado, que
} 
se organiza y opera políticamente se puede denominar fuerte, en tanto que funciona autárquicamente frente a otras comunidades. En este aspecto se muestra el genuino estilo teológico - jurídico de nuestro autor.

\section{Notas finales}

Hemos reunido diversos aspectos del pensamiento de Suárez mostrando que "va lejos, más allá de meramente alinearse a sí mismo con un antiguo maestro medieval. En muchas áreas y de muchas maneras fue un innovador de importantes ideas modernas prístinas" ${ }^{94}$. Suárez se asocia a la filosofía moderna; no obsante, se distingue de aquella nueva ciencia moderna de Copérnico, Galileo o Kepler en el inicio del siglo XVII, tampoco él se inscribe en la corriente renacentista de Petrus Ramus (15151572) y Francis Bacon (1561- 1626), quienes reemplazan las Categorías de Aristóteles por los Ars Intelectualis para modificar la retórica, e introducir una enseñanza en la ciencia, exigiendo un lenguaje simple, para que la pruebas hablen por sí solas, y así, dar paso a una manera novedosa de interrelacionar todas las artes con el lenguaje ${ }^{95}$. En este sentido la intención de Suárez no es siquiera la primacía que Descartes otorga a la formulación de las regulae metódicas para que la bonae mentis distinga el buen, del mal razonamiento. En lo que resumimos se pudo notar que la modernidad de Suárez es filosófica; efectivamente incluye diversas novedades y reformulaciones en las áreas especulativas de la filosofía. De sus

garantice la sostenibilidad y el buen vivir, Sumak Kawsay”, en la que se explicita además que esa es la finalidad última del desarrollo." (Cf. Victor Bretón, David Cortez, Fernando García, "En busca del sumak kawsay”, Ikonos, 48 (2014): 9-24.

94 The Philosophy of Francisco Suárez (Oxford: Oxford University Press, 2012), 4, eds. Benjamin Hill, Henrik Lagerlund.

${ }^{95}$ Francis Bacon en The Advancement of Learning había defendido que la retórica tiene obligaciones tanto con el discurso científico como con el popular, obligaciones más comprensivas y vitales que los que ofrece el sistema tradicional de la retórica. (The Oxford Francis Bacon. The Advancement of Learning, vol. IV, ed. Michael Kierman (Oxford University Press, 2000)). 
innovaciones Suárez está consciente, pero él mismo quiere explicar en sus términos que "a menudo [se trata de] nuevos nombres para las cosas mejor explicadas" $"$.

Así pues, en metafísica Suárez inaugura para la modernidad, y por la misma razón de D. Scotus, una metafísica como ciencia transcendental, porque su objeto es el concepto de ser o ratio entis, y precisamente para ambos filósofos el concepto o "la razón de ente es trascendental". Pero, a diferencia de D. Scotus, la base de la argumentación transcendental de Suárez es la unidad del concepto objetivo del ser, y su transcendentalidad queda garantizada por la primacía parcial de la argumentación a priori por sobre la argumentación de experiencia. Esta doctrina se puede considerar un antecedente de la fenomenología, con la ventaja que ve Esposito ${ }^{97}$, en tanto que: se trata de una metafísica pura. En la cual se requiere la sola condición de un mínimo, i.e.: el concepto de ser en cuanto ser (como ser real), y todas las referencias al origen del ser pueden dejarse de lado. Se debe notar, sin embargo, que Suárez no dice que debemos dejar de lado tal referencia, sino sólo que podemos; y esto es suficiente para una fundamentación natural del orden del ser. Por otra parte, el carácter preparatorio de la metafísica como distinta de la teología, no debe entenderse en el sentido que la metafísica carece de la base definitiva que la teología puede darle, sino sólo en el sentido que la metafísica debe proveer primero los conceptos básicos necesarios para desarrollar el discurso sobre la revelación supernatural.

En epistemología, Suárez elabora una auto-reflexividad y autoproducción del concepto divino, lo que se ve apropiado por Hegel en su circularidad auto-productiva del concepto, como se vio en la interpretación de Zubiri y Lozano ${ }^{98}$. En filosofía de la mente, paradigmáticamente Suárez insiste que tenemos una conciencia reflexiva de nuestros propios actos psíquicos/lógicos. Por lo que en el lenguaje mental, los conceptos simples

\footnotetext{
96 Suárez, (OTS II 4), 353.

${ }^{97}$ Esposito, “The Hidden Influence of Súarez on Kant's Transcendental Conception of 'Being', 'Essence and 'Existence", in (SMHC), 120.

${ }^{98}$ Lozano, $(S \& H), 253$.
} 
adquieren valor semántico; son: verdaderos o (metafóricamente) falsos, términos mentales reales; el significado de palabras y proposiciones; lo que es conocido y permite conocer; lo que es percibido o aprehendido por la mente; lo que es claro y distinto (o confuso); lo que es translúcido para un sujeto; lo que connota otras cosas, sea objetos o ideas-conceptos, lo que es instrumento de la acción. De modo que este es el marco y la dirección ineludible que determinó el giro mentalista en la filosofía moderna, desde Descartes, Leibniz, Wolf, Kant, Hegel, Schopenhauer, a Nietzsche, Heidegger, Pierce y Whitehead.

En filosofía moral, dentro de la corriente distintiva jesuita, donde se enfatiza la libertad y la autonomía del individuo frente a los grupos impositivos del poder, Suárez concibe, primero, un individuo en proceso moral 'ordenado a otro' que "no solamente aprende, sino también al aprender ve, al ver desea, y al desear se realiza" 99 . El individuo se realiza singular y concretamente, con otros, conectado a una colectividad. En segundo lugar, modela una moderna relación entre el individuo, la colectividad y el Estado, en que el Estado sirve al sistema comunitario soberano y público de los individuos reunidos e intercomunicados en colectividad. Propone poner en práctica un sistema de derecho -reuniendo dos corrientes, la teológica y jurídica, que hasta entonces habían discurrido por separado-, donde la horizontalidad de la ley y la justicia distributiva legal, convierten el bien común en deber específico de la colectividad y de cada uno de sus miembros ciudadanos, de quienes, bajo condiciones de equidad de deberes y fines acordados, resultará mayor bienestar social que equivale a caminar hacia el cumplimiento y prosperidad de la humanidad.

En suma, la modernidad filosófica de Suárez se contrapone a la notoria primacía epistemológica que Descartes otorga a lo simple, en el contexto de lo propedéutico para la investigación de la bona mens o le bon sens en el estilo de las Regulae (1628) y en el Discours de la méthode (1637). Lo cual se explica, porque el interés de Suárez por el conocimiento de lo simple está orientado al mor del conocer dentro de la complejidad de las

\footnotetext{
${ }^{99}$ Suárez, (OTS II 4 5), 355.
} 
relaciones que se pueden establecer desde la teología trinitaria, hasta la dinámica relación del hombre, mundo y Dios. Esta se concibe modernamente junto al devenir fáctico que lo sugiere. La complejidad unitaria del pensamiento de Suárez, de acuerdo a José Pereira, conforma un "Super-sistema" estructurado en torno a los conceptos de ser, Dios, creación y causalidad final ${ }^{100}$.

Data de registro: 16/09/2021

Data de aceite: 01/12/2021

${ }^{100}$ José Pereira, Robert Fastiggi, The Mystical Theology of the Catholic Reformation (Lanham, M. D.: University Press of America), 264- 272 